\title{
A STUDY ON PRODUCTION OF BANANA FROZEN YOGHURT AND ASSESSING CONSUMER ACCEPTABILITY
}

\author{
Petra W.M.A.D ${ }^{1}$, Gunasena A.R.C ${ }^{1}$, Perera H.S.S ${ }^{1}$, Hathurusinghe M.H ${ }^{1} \square$ \\ ${ }^{1}$ Department of Veterinary Public Health and Pharmacology, Faculty of Veterinary Medicine and Animal \\ Science, University of Peradeniya, Sri Lanka.
}

Received 7 November 2021

Accepted 17 December 2021

Published 31 December 2021

CorrespondingAuthor

Hathurusinghe M.H, madhaviha@yahoo.com

DOI

10.29121/granthaalayah.v9.i12.2021 .4425

Funding: This research received no specific grant from any funding agency in the public, commercial, or not-for-profit sectors.

Copyright: (C) 2021 The Author(s). This is an open access article distributed under the terms of the Creative Commons Attribution License, which permits unrestricted use, distribution, and reproduction in any medium, provided the original author and source are credited.

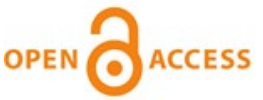

\section{ABSTRACT}

Frozen yogurt is a frozen dairy dessert made with yogurt. It's known for its frozen texture as a dessert and higher nutritional value in comparison with ice cream. Frozen yogurt is used much like ice cream and served in a wide variety of flavors and styles around the world. The objective of this project was to develop a healthier frozen yoghurt with natural banana flavour, and to evaluate its sensory acceptability. Banana frozen yoghurt was produced with vanilla and chocolate flavors. The sensory acceptability of products was tested at Department of Veterinary Public health and Pharmacology (VPHP) by conducting two sensory panels. According to the results, in sensory analysis both vanilla and chocolate flavored products were equally accepted. Further studies need to be carried out to improve the product with a higher probiotic value and better texture.

Keywords: Frozen Yogurt, Sensory Acceptability

\section{INTRODUCTION}

Yoghurt is one of the popular and oldest fermented dairy products around the world. Yoghurt is a healthy food because it contains viable bacteria that are considered as probiotics. It is preferred by people in all ages in different communities, due to its nutritive value and health benefits Mazahreh and Ershidat (2009). Yoghurt is also rich in nutrients such as protein, carbohydrates, vitamins, phosphorus and calcium. It is typically produced by adding conventional starter culture including mainly Lactobacillus bulgaricus and Streptococcus thermophilus which produce lactic acid as a byproduct of fermentation. During fermentation process lactose of milk is digested therefore yoghurt easily digested Yildiz (2016)

Frozen yoghurt is becoming increasingly popular around the world. It is a fermented dairy dessert that is a combination of yoghurt and ice cream Güven et al. (2002). The physical quality of frozen yoghurt is similar to ice cream whereas the sensory and nutritional benefits are mostly related to yoghurt. Frozen yoghurt is considered a healthier alternative to ice cream due to its low-fat content and mostly recommended for the consumers with heart disease, or lactose intolerance Pratap et al. (2015).

Milk and dairy products do not contain fiber. Fiber is found in the cell wall of fruits, vegetables, and cereals Lunn (2007). Incorporation of dietary fiber in making yoghurt will make it even healthier. The dietary fiber will also enhance the consumer acceptability due to the improvement of colour, flavor and texture Hashim et al. (2009). 
Incorporation of fruit in yoghurt manufacture has been attempted around the world and it makes yoghurt more delicious. This will also give yoghurt a pleasing flavour of fruit and enhance beneficial effect of yoghurt. Several research have carried out to add fruity ingredients to frozen yoghurt recipes to increase the acceptance García-Pérez et al. (2005). Sendra et al. (2008). In order to make value-added yogurt, FAO and WHO recommend using 5\%-15\% percent fruit concentration Analianasari and Apriyani (2018). Consistency viscosity and mouth feel of yoghurt can be enhanced by adding fruit pectin and fructose Shiv et al. (2015). Banana is one of the widely available local fruits in Sri Lanka that can be used to flavor frozen yogurt. Therefore, the objective of this project was to develop a healthier frozen yoghurt with natural banana flavour, and to evaluate its sensory acceptability.

\section{MATERIALS AND METHODS Ingredients}

Fresh cow's milk was obtained from the University farm. Gelatine, sugar, vanilla extract, banana, bee's honey, rice flour, cocoa powder, cashew nuts and chocolate chips were obtained from the local market. The yoghurt starter culture (containing streptococcus thermophilus and lactobacillus bulgaricus) was obtained from Veterinary Research Institute, Gannoruwa, Sri Lanka.

\section{Preparation of plain yoghurt}

Milk was boiled while stirring at boiling temperature for 3-5 minutes. Gelatine (5g/1itre of milk) and sugar $(80 \mathrm{~g} / 1 \mathrm{~L}$ of milk) was added separately while boiling. Milk was taken out of the fire and allowed to cool while stirring. When the temperature of milk became $450 \mathrm{C}$, yoghurt starter culture was added to milk (2\%) while mixing. The mixture was poured into plastic cups ( $80 \mathrm{ml} / \mathrm{cup}$ ) and incubated at $420 \mathrm{C}$ for 5-6 hours.

\section{Preparation of Vanilla Flavored Banana Frozen Yogurt}

The required amounts of yoghurt (40g), Banana (50g), Vanilla (2.5ml), Bee's honey $(3.75 \mathrm{ml})$, Rice flour $(1.25 \mathrm{~g})$ were added in the food processor and mixed until it gave a creamy texture. The mixture was added to plastic cups $(80 \mathrm{~g} / \mathrm{cup})$ and $5 \mathrm{~g}$ of chocolate chips were sprinkled over. The cups were kept at -200 C freezer for 24 hours and taken out 15 minutes before serving.

\section{Preparation of Chocolate Flavored Banana Frozen Yogurt}

The required amounts of yoghurt (40g), Banana (50g), Cocoa powder (6g), Bee's honey (3.75ml), Rice flour (1.25g) were added in the food processor and mixed until it gave a creamy texture. The mixture was added to plastic cups (80g/cup) and $5 \mathrm{~g}$ of chopped cashew nuts were sprinkled over. The cups were kept at -200 C freezer for 24 hours and taken out 15 minutes before serving.

Four types of frozen yoghurt including vanilla flavored with and without honey and chocolate flavored with and without honey was prepared (Figure 1) and subjected to sensory evaluation. 


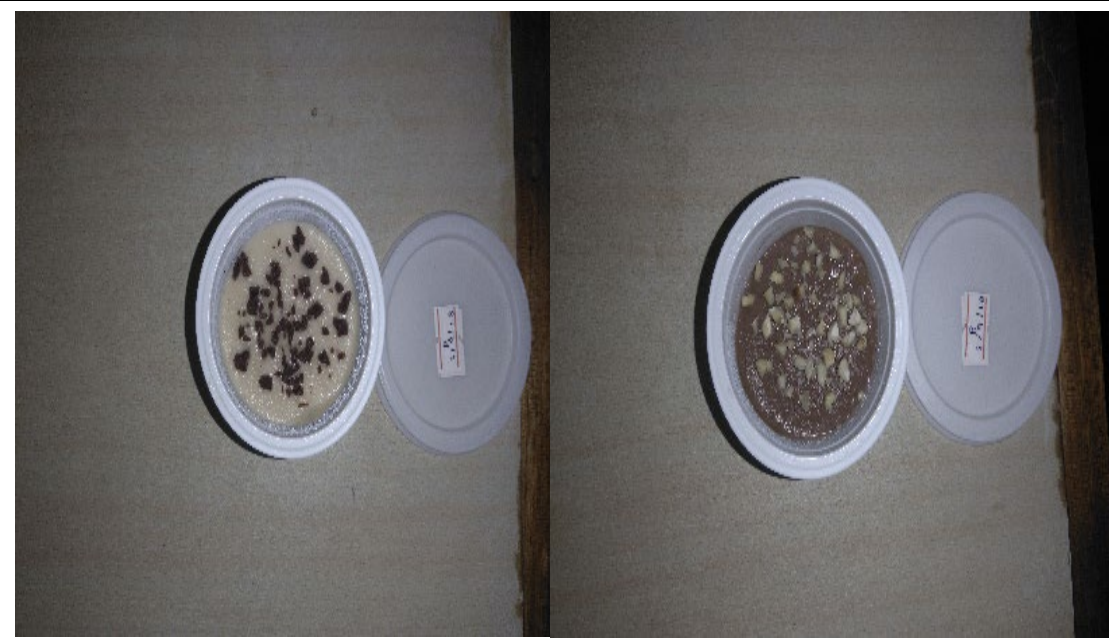

Figure 1 Vanilla flavored and Chocolate flavored frozen yoghurt

Frozen yoghurt samples were scored by 30 untrained panelists including the staff members and students of Faculty of Veterinary Medicine and Animal Science, University of Peradeniya. Appearance, taste, texture, sweetness and overall acceptance were assessed by the panelists. A five-point hedonic scale was used where 1 =dislike very much to $5=$ like very much.

\section{Statistical Analysis}

The collected data were analyzed using statistical analysis program SPSS. ANOVA was used to determine the significant difference between frozen yoghurt samples.

\section{RESULTS AND DISCUSSION}

Chocolate and vanilla flavored frozen yogurt were made with and without Bee`s honey (Figure 1). According to the results the best score (3.5) for appearance was obtained by chocolate flavored honey added frozen yoghurt whereas the best score (4.0) for taste was obtained equally by both chocolate and vanilla flavored honey added frozen yoghurt (Table 1). This may be due to the fact that adding bees' honey may have improved the texture and the overall appearance of the yoghurt.

The highest score (4.0) for sweetness was obtained by chocolate flavored honey added frozen yoghurt (Figure 3). This shows that the panelists' perceptions of taste were linked to the total sugar content. The taste was more likeable as the overall sugar content increased. The best score for overall acceptance was obtained by chocolate flavored honey added frozen yoghurt and the least score for overall acceptance was obtained by vanilla flavored frozen yoghurt. Among the vanilla flavored yoghurt panelists preferred the vanilla flavored honey added yoghurt (Figure 2) than vanilla favored frozen yoghurt without honey.

In comments panelists have suggested to improve the appearance of products and to reduce the chocolate flavor in chocolate products since it added strong color and taste. 


\begin{tabular}{|ccccc}
\hline \multicolumn{5}{l}{ Table 1 Sensory characteristics of frozen yoghurt } \\
\hline Sensory Score & \multicolumn{5}{c}{ Type of Frozen Yoghurt } \\
\hline Sensory characteristic & Vanilla & Vanilla + honey & Chocolate & Chocolate + honey \\
\hline Appearance & 3 & 3 & 3 & 3.5 \\
Taste & 2.5 & 4 & 3.5 & 4 \\
\hline Texture & 3 & 3.5 & 3.5 & 3 \\
\hline Sweetness & 2.5 & 2.5 & 3.5 & 4 \\
\hline Overall acceptance & 3 & 3.5 & 3.5 & 4 \\
\hline
\end{tabular}

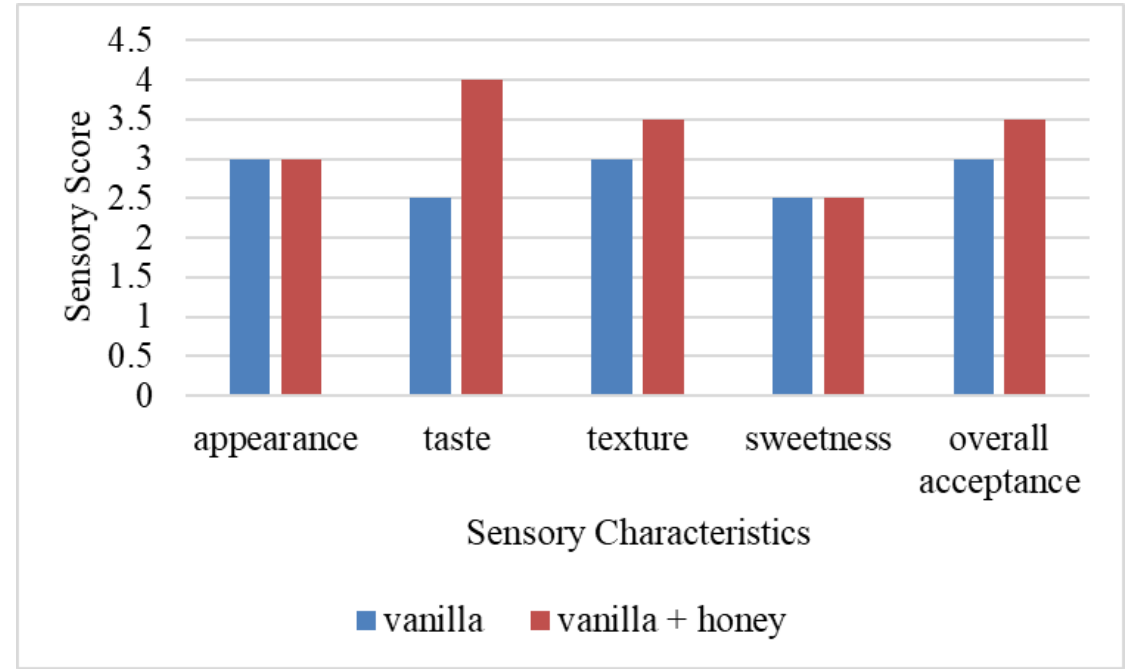

Figure 2 Sensory characteristics of vanilla flavored frozen yogurt

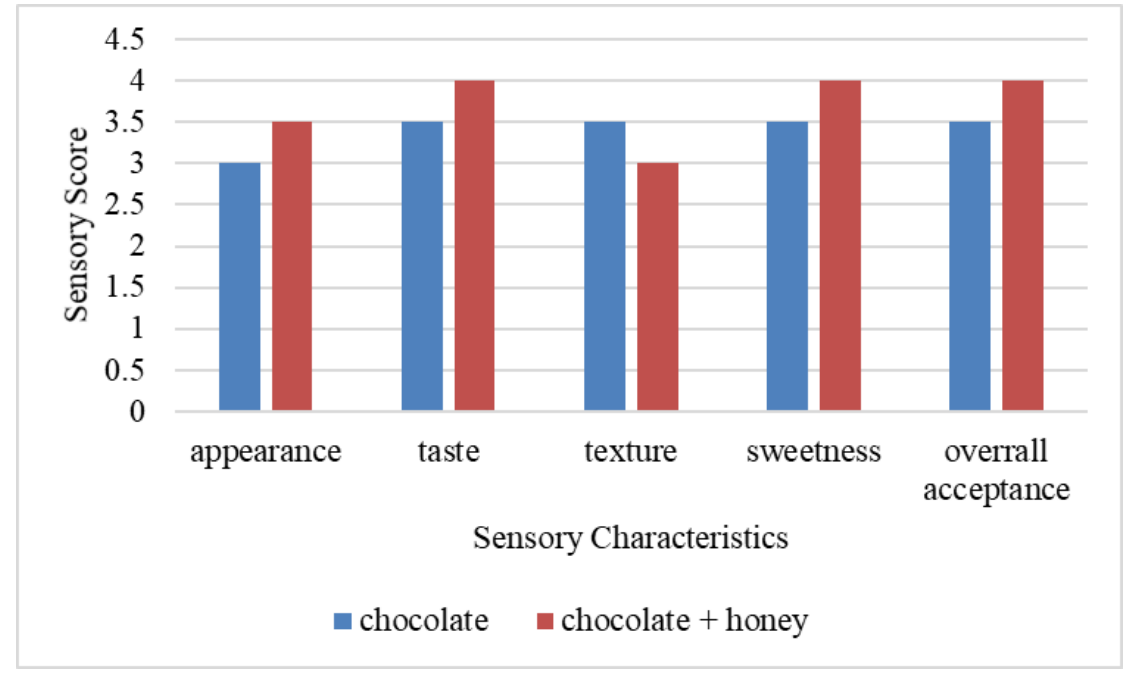

Figure 3 Sensory characteristics of chocolate flavored frozen yogurt

\section{CONCLUSIONS AND RECOMMENDATIONS}

According to the results, in sensory analysis both vanilla and chocolate flavored products were equally accepted. The evidence from this study suggests that addition of natural banana flavour increased acceptability of frozen yoghurt. Even though fermented dairy desserts such as yoghurt and curd are quite famous around the 
world frozen yoghurt is still remains less recognized in countries like Sri Lanka. Therefore, it is very important to conduct further studies to develop fruit flavored fermented dairy desserts which will enhance the nutritional and health benefits delivered to consumers.

\section{REFERENCES}

Analianasari and Apriyani M. (2018). Characteristics of Frozen Yoghurt Enriched with Red Dragon Fruit Skin Extracts (Hylocereus polyrhizus). J. Phys. Conf. Ser., 953 12036. Retrieved from https://doi.org/10.1088/17426596/953/1/012036

García-Pérez, F. J., Lario, Y., Fernández-López, J., Sayas, E., Pérez-Alvarez, J. A., \& Sendra, E. (2005). Effect of orange fiber addition on yogurt color during fermentation and cold storage. Color Research and Application, 30(6), 457463. Retrieved from https://doi.org/10.1002/col.20158

Güven, M., Karaca, O. B., \& Güven M and Karaca O B. (2002). The effects of varying sugar content and fruit concentration on the physical properties of vanilla and fruit ice-cream -type frozen yogurts. Int. J., 27-31, Tec (1), 27-31. Retrieved from https://doi.org/10.1046/j.1471-0307.2002.00034.x

Hashim, I. B., Khalil, A. H., \& Afifi, H. S. (2009). Quality characteristics and consumer acceptance of yogurt fortified with date fiber. Journal of Dairy Science, 92(11), 5403-5407. Retrieved from https://doi.org/10.3168/jds.20092234

J. Lunn, J. L. B. (2007). Carbohydrates and dietary fiber. Nutr. Bull, 32, 21-64. Retrieved from https://doi.org/10.1111/j.1467-3010.2007.00616.x

Mazahreh, A. S., \& Ershidat, O. T. M. (2009). The benefits of lactic acid bacteria in yogurt on the gastrointestinal function and health. Pakistan Journal of Nutrition, 8(9), 1404-1410. Retrieved from https://doi.org/10.3923/pjn.2009.1404.1410

Pratap Y S M, Chandra R, S. S. and A. M. N., Shiv, Y., Pratap, M., Chandra, R., Shukla, S., \& Ali, N. (2015). Optimization of The Chemical Properties of Frozen Yogurt Supplemented with Different Fruit Pulp. Pharma Innov, J. 4 56-(2), 56-58. Retrieved from https://www.thepharmajournal.com/vol4Issue2/Issue_Apr_2015/4-234.1.pdf

Sendra, E., Fayos, P., Lario, Y., Fernández-López, J., Sayas-Barberá, E., \& PérezAlvarez, J. A. (2008). Incorporation of citrus fibers in fermented milk containing probiotic bacteria. Food Microbiology, 25(1), 13-21. Retrieved from https://doi.org/10.1016/j.fm.2007.09.003

Shiv, Y., Pratap, M., Chandra, R., Shukla, S., \& Ali, N. (2015). Optimization of the chemical properties of frozen yoghurt supplemented with different fruit pulp. 4(2), 56-58.

Yildiz, F. (2016). Development and manufacture of yogurt and other functional dairy products. Development and Manufacture of Yogurt and Other Functional Dairy Products, Boca Raton (FL), 1-435. Retrieved from https://doi.org/10.1201/9781420082081 